\title{
Biodiesel Produced in Eucalyptus Oil and Analyzed for Various Characteristics
}

\author{
A.Akhil, CM.Santosh Kumar Reddy, B.Balaj
}

\begin{abstract}
Eucalyptus oil changed into selected as the wellspring of biodiesel and the specific attributes were broke down. The eucalyptus tree is a non-eatable animal categories healthy for growing in each single climatic situation. Eucalyptus oil was gotten for the maximum component from the leaves of the tree and is offered continuously. When the unadulterated eucalyptus oil has been extricated, it turned into modified over into biodiesel through the method of transesterification. The physico-synthetic homes of the biodiesel in this way got had been broke down and contrasted with the diesel with discover its reasonableness for use in diesel cars
\end{abstract}

\section{INTRODUCTION}

Consumption of non-renewable power resources, ecological issues introduced about by expanded emanations and the lofty climb inside the price of oil primarily based goods are becoming one of the

maximum widespread issues appeared with the aid of the prevailing reality. Non-renewable power assets have consistently been the number one wellspring of vitality for the power advent and transportation elements of the sector. The way that the non-renewable power supply saves have become exhausted step by step is leaving the sector in query. It is the right possibility for us to give proper consideration to locating other sustainable fuel assets which can be utilized as optionally available powers to the everyday energizes - petroleum and diesel.

\section{WRITING REVIEW \& METHODOLOGY}

Tamil vendhan.D et al. Dissected the presentation of biodiesel were given from Eucalyptus oil and its mix with rapid diesel in a Ricardo E6 motor. The decreases in fumes discharges and brake explicit gasoline usage collectively with increment brake manipulate, brake heat productivity made the mix of biodiesel (B20) a reasonable elective fuel fordiesel.

N.S.Senthur et al attempted biodiesel on a solitary chamber, four stroke pressure begin motor. Motor execution assessments verified that strength misfortune changed into around thirteen $\%$ joined with $20 \%$ expansion in gasoline utilization with Eucalyptus oil methyl ester at complete burden. Discharges, for example, carbon monoxide, hydrocarbon become lesser for Eucalyptus ester contrasted with diesel by using $26 \%$ and $20 \%$ one at a time. Oxides of nitrogen had been lesser by using $4 \%$ for the ester contrasted with diesel. K.Anandavelu et al in his examination,

Revised Manuscript Received on September 14, 2019.

A.Akhil, Department of Mechanical Engineering, Siddhartha Institute of Technology \& Sciences, Narapally, Hyderabad, Telangana, India.

CM.Santosh Kumar Reddy, Department of Mechanical Engineering, Siddhartha Institute of Technology \& Sciences, Narapally, Hyderabad, Telangana, India.

B.Balaj, Department of Mechanical Engineering, Siddhartha Institute of Technology \& Sciences, Narapally, Hyderabad, Telangana, India.
Eucalyptus Oil Ethyl Ester became set up by way of transesterification utilising sulfuric corrosive ( $\mathrm{H} 2 \mathrm{SO} 4)$ as impetus. Results indicated that brake warm productivity of Eucalyptus Oil Ethyl Ester (MOEE) turned into practically identical with diesel and it was seen that $26.36 \%$ for diesel while $26.42 \%$ for MOEE. Discharges of carbon monoxide, hydrocarbons, oxides of nitrogen and Bosch smoke variety have been decreased around58, 63,

12 and $70 \%$, respectively.Sharanappagodiganur, et al broke down the utilization of biodiesel gasoline an alternative for regular oil gas in rock stable diesel motor. The results display that with the growth of biodieselin

the mixes $\mathrm{CO}, \mathrm{HC}$ decreases fundamentally, gasoline utilization and NOx discharge of biodiesel increments fairly contrasted and diesel. Gauravatravalkar, vijaydesale, aakashnemade et al broke down the Vegetable oils offer a preferred position of equal gas properties with diesel. The calorific estimation of Eucalyptus oil changed into discovered as $96.30 \%$ on volume premise of diesel. It become determined that Eucalyptus could be correctly substituted up to $20 \%$ in diesel with no massive contrast in control yield, brake specific fuel utilization and brake heat productivity. The presentation of motor with Eucalyptus oil mixes improved with the growth in pressure percentage from sixteen:1 to 20:1.

\section{BIODIESEL}

Biodiesels are created from vegetable oils by using a technique known as transesterification. Transesterification consists of the reaction of the vegetable oil with a liquor, within the sight of an impetus, to border Esters and glycerol. These esters are alluded to as biodiesels and they can be utilized inCompressionIgnitionengineseitherasa

A solitary gasoline (ideal biodiesel) or via mixing in with petro-diesel in distinct extents. Numerous biodiesel, were given from vegetable oil sources are brilliant, have been attempted as an choice in assessment to diesel gasoline for pretty a while. Past research here suggests that the utilization of biodiesel produces a presentation much like a diesel fuel with the extra gain of lower discharges. Biodiesel is likewise predicted to lower mileage at the system when the diesel motor is located to have preferred oil properties over petro-diesel.

\section{Eucalyptus Oil}

\section{Apparatusused}

1. Copper tube

2. Eucalyptus leaves and water 
three. The warmth source (eg, a Bunsen burner)

4. Cooling tank (ie, bathe toddler containingwater)

5. Adaptable elastic pipe

6. Glass collectionjar

\section{Exploratory PROCEDURE \& Results}

1. In the arrangement of biodiesel Eucalyptus, ethyl transesterification embraced. Methanol is utilized because the liquor in the readiness eucalyptusbiodiesel.

2. Unadulterated eucalyptus oil taken in a check tube. The extent of $500 \mathrm{ml}$ of unadulterated eucalyptus oil, a hundred $\mathrm{ml}$ of methanol and $5 \mathrm{~g} \mathrm{NaOH}$ pellets as an impetus.

Three. $\mathrm{NaOH}$ pellets broke up in methanol arrangement was taken in a measuring utencil. After all $\mathrm{NaOH}$ pellet is definitely broken up, the arrangement may be known as Sodium methoxide arrangement.

Blending sodium methoxide SOLUTIONS AND EUCALYPTUS OIL
1. The arrangement received was then introduced to the unadulterated eucalyptus oil in a pitcher and it become warmed and blended altogether for round one hour at fifty five ${ }^{\circ}-65^{\circ}$. The blending process is described through a mix of yellow staining are obvious to ruddy yellow.The

the acquired arrangement is then stuffed a carafe topsy turvy and permitted to make due with 24 hours nearly.

2. Glycerol Then it will settle at the bottom of the pumpkin as a dull darker shaded fluid and methyl esters (biodiesel unsightly) will be formed at the pinnacle. Glycerol changed into evacuated and harsh biodiesel washeated

over one hundred $\mathrm{C}$ to expel methanol untreated.

3. $\mathrm{NaOH}$ soil is evacuated by using washing with water. Biodiesel cleaned so got is Eucalyptus oil methyl ester, noted just as Eucalyptus biodiesel

\section{RESULTS FOR DF60 EUB40}

\begin{tabular}{|c|c|c|c|c|c|c|c|c|c|c|c|c|}
\hline 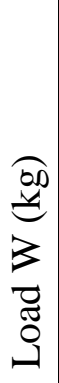 & 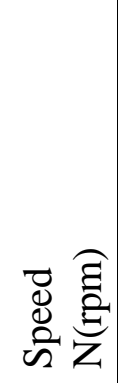 & 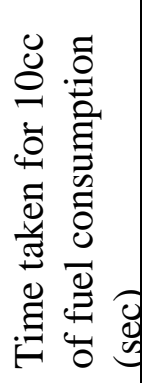 & 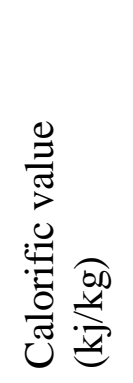 & 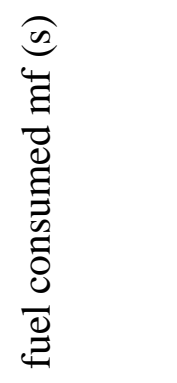 & 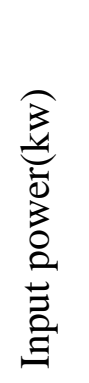 & 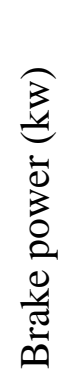 & 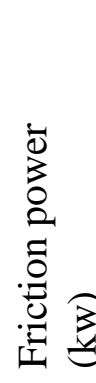 & 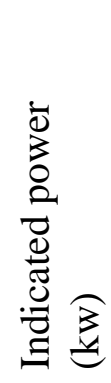 & 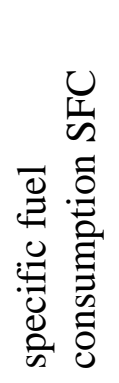 & 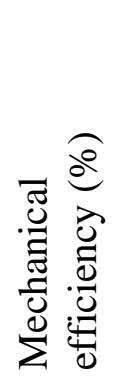 & 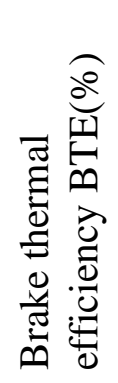 & 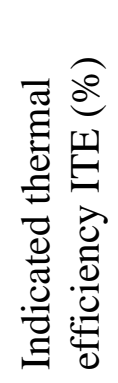 \\
\hline 0 & 1515 & 88 & 42928 & $9.39 \mathrm{E}^{-5}$ & 4.03 & 0 & 1.5 & 1.5 & 0.98 & 0 & 0 & 37.18 \\
\hline 2 & 1510 & 58 & 42928 & 0.000142 & 6.12 & 0.7 & 1.5 & 2.26 & 0.70 & 32.69 & 11.90 & 36.41 \\
\hline 4 & 1493 & 44 & 42928 & 0.000187 & 8.06 & 1.4 & 1.5 & 2.94 & 0.46 & 48.99 & 17.85 & 36.45 \\
\hline 6 & 1489 & 38 & 42928 & 0.000217 & 9.34 & 2.1 & 1.5 & 3.65 & 0.36 & 58.96 & 23.07 & 39.12 \\
\hline 7 & 1482 & 24 & 42928 & 0.000344 & 14.7 & 2.5 & 1.5 & 4.00 & 0.49 & 62.52 & 16.92 & 27.06 \\
\hline
\end{tabular}

RESULTS FOR STANDARD DEISEL

\begin{tabular}{|c|c|c|c|c|c|c|c|c|c|c|c|c|}
\hline 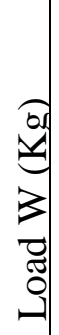 & 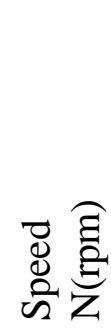 & 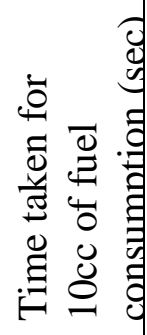 & 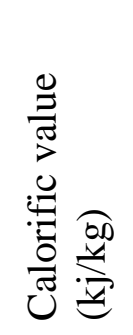 & 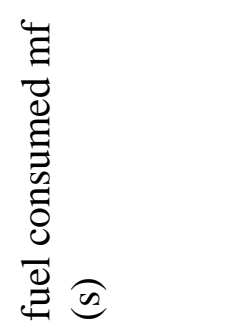 & 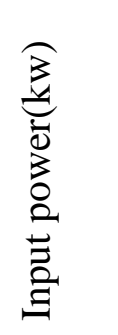 & 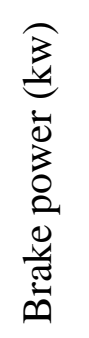 & 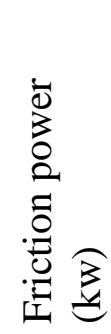 & 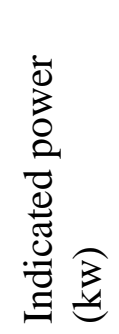 & 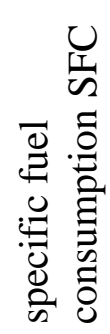 & 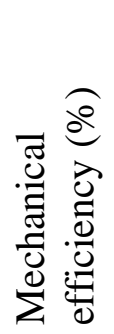 & 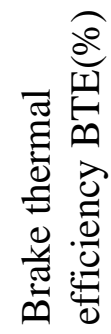 & 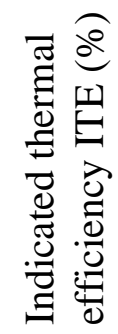 \\
\hline 0 & 1548 & 79 & 42700 & 0.000104684 & 4.46 & 0 & 1.5 & 1.5 & & 0 & 0 & 33.55 \\
\hline 2 & 1536 & 53 & 42700 & 0.000156038 & 6.66 & 0.74 & 1.5 & 2.24 & 0.75 & 33.07 & 11.12 & 33.63 \\
\hline 4 & 1525 & 42 & 42700 & 0.000196905 & 8.40 & 1.47 & 1.5 & 2.97 & 0.48 & 49.52 & 17.50 & 35.34 \\
\hline 6 & 1510 & 34 & 42700 & 0.000243235 & 10.38 & 2.18 & 1.5 & 3.68 & 0.40 & 59.30 & 21.04 & 35.49 \\
\hline 7 & 1490 & 25 & 42700 & 0.0003308 & 14.12 & 2.51 & 1.5 & 4.01 & 0.47 & 62.65 & 17.81 & 28.43 \\
\hline
\end{tabular}




\section{BRAKE THERMAL EFFICIENCY \& RESULTS}

The picture shows a generally higher brake warm effectiveness to DF60Eu40 blend contrasted with diesel fuel, at all heaps. This might be brought about by the nearness of eucalyptus oil unpredictable high in the blend. A decline in thickness prompts expanded atomization, fuel dissipation and ignition. It might likewise be because of better usage of warmth vitality and a superior air entrainment. The nearness of eucalyptus oil in the blend creating additional defers start and fast burning. This prompts a higher chamber weight and brake warm proficiency is higher. Brake warm productivity DF60Eu40atfullloadis17\% moreorless

same of standard diesel operation.

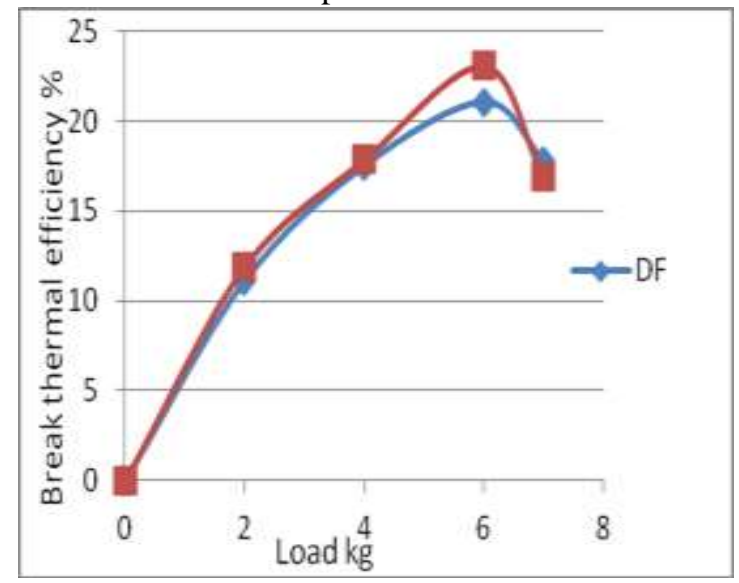

Variation of break thermal efficiency with load for various DF60EUB40

\section{Brake Specific Energy}

Consumption (BSEC)

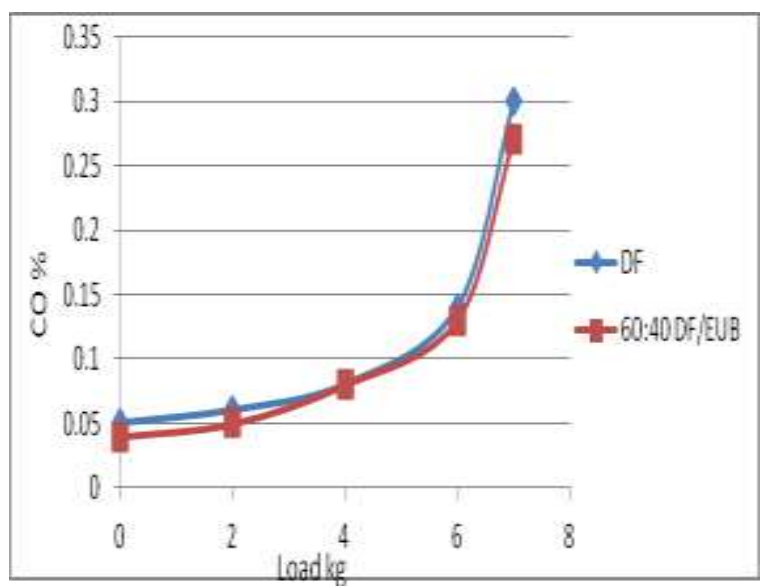

The figures show that at low loads BSEC is $75 \mathrm{MJ} / \mathrm{kWhr}$ for diesel and for DF60Eu40 mixture is 70MJ / $\mathrm{kWhr}$. At full load the BSEC is 47MJ / $\mathrm{kWhr}$ for diesel and for DF60Eu40 mixture is 40MJ / $\mathrm{kWhr}$. The energy consumption of a specific brake DF60Eu40 mixture is lower than all other blends and diesel standards. This may be due to better combustion and increased energycontent that.

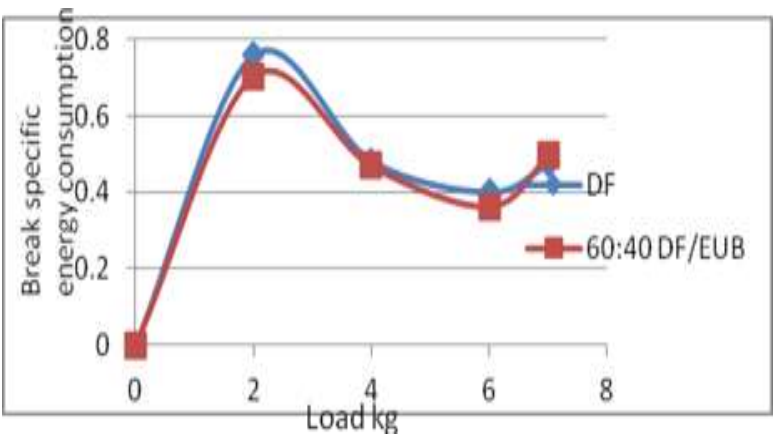

Variation of break specific energy consumption with load for various DF60EUB40

\section{Emission Analyses}

\section{CO emission}

This figure shows the $\mathrm{CO}$ emanations from DF60Eu40 blend in with an assortment of burdens. At low and medium burden, $\mathrm{CO}$ discharges of the blend isn't a lot of contrast from the standard diesel fuel activity. DF60Eu40 blend CO outflows diminished fundamentally at full burden. This might be brought about by oxygen enhancement in eucalyptus oil in which the expansion in the extent of oxygen advances further oxidation of $\mathrm{CO}$ during the procedure of motor fumes. There is a $37.5 \%$ decrease of $\mathrm{CO}$ emanations to blend DF60Eu40 at full burden. Varieties of carbon monoxide with burdens to variousDF60EUB40

HC emanations

Figures show that the variety of HC outflows DF60Eu40 fuel blend under various motor burden. $\mathrm{HC}$ level increments with expanding load on diesel and blends. It is seen that the $\mathrm{HC}$ discharges for diesel fuel is $7 \mathrm{ppm}$ and 19ppm burden atlow

at full burden and for DF60Eu40 blend that is $10 \mathrm{ppm}$ at low burden and $20 \mathrm{ppm}$ at full burden. For DF60Eu40 blend, higher $\mathrm{HC}$ discharges than diesel fuel, and this might be because of inadequate burning.

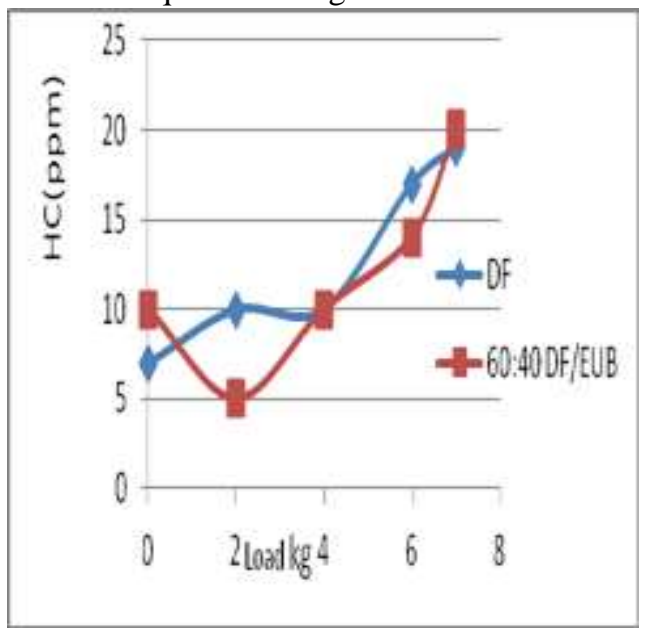

Variation of hydrocarbon emission with load for various DF60EUB40 


\section{Oxides of Nitrogen (NOx)}

The image shows that the various NOx out to mix diesel DF60Eu40 and standards for various motor loads. Expansion in the pattern may be due to the proximity of oxygen in eucalyptus oil. Many analysts are details that can oxygenate the fuel mixture led to an expansion in NOx emanation. Regular complete combustion causes a higher ignition temperature which carry higher NOx settings. Other

The explanation behind the expansion in discharge of NOx is stifling cetane owned eucalyptus oil. Typically, the strength of the low cetane offer again began to defer and discharge more warmth during periods of premixed ignition. For DF60Eu40 mixture, which NOxemission was34ppm.

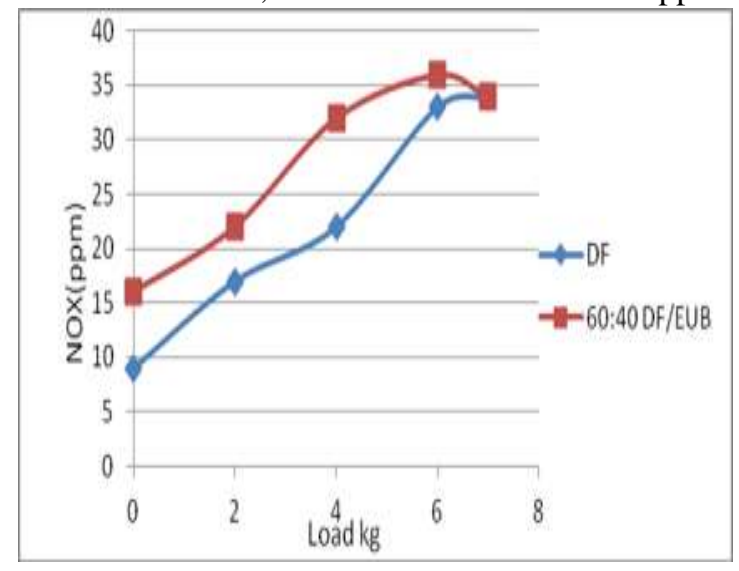

Variation of NOx emission with load for various DF60EUB40

\section{CO2 emission:}

guardians show CO2 emanations from DF60Eu40 blend in with an assortment of burdens. At low and medium mass, the $\mathrm{CO} 2$ outflows of the blend has no longer quite a bit of a distinction from the normal diesel gas tasks. CO2 emanations from DF60Eu40 blend diminished essentially at full burden. This is likely dueto

oxygen improvement in eucalyptus oil in which the development in the portion of the expansion of oxygen to advance oxidation of $\mathrm{CO} 2$ at a few points by methods for motor fumes. There transformed into a decrease of $\mathrm{CO} 2$ discharges to blend DF60Eu40 in fullload.

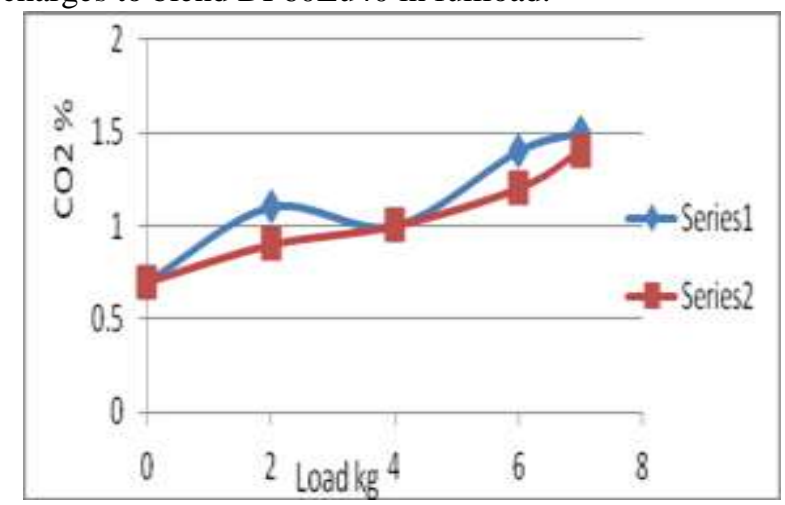

Variation of $\mathrm{CO} 2$ emission with load for various DF60EUB40

\section{O2 emission:}

The figure shows the $\mathrm{O} 2$ outflow of DF60Eu40 mixes with different burdens. At low and medium burdens, O2 outflows of the mixes were very little distinction from standard diesel fuel activity. The O2 discharge of DF60Eu40 mixes expanded fundamentally at full burden. This might be because of the improvement of oxygen in the eucalyptus oil in which an expansion in the extent of oxygen advances further oxidation of $\mathrm{O} 2$ during the motor fumes process. Therewas increase of $\mathrm{O} 2$ emissionfor the DF60Eu40 blend at fullload.

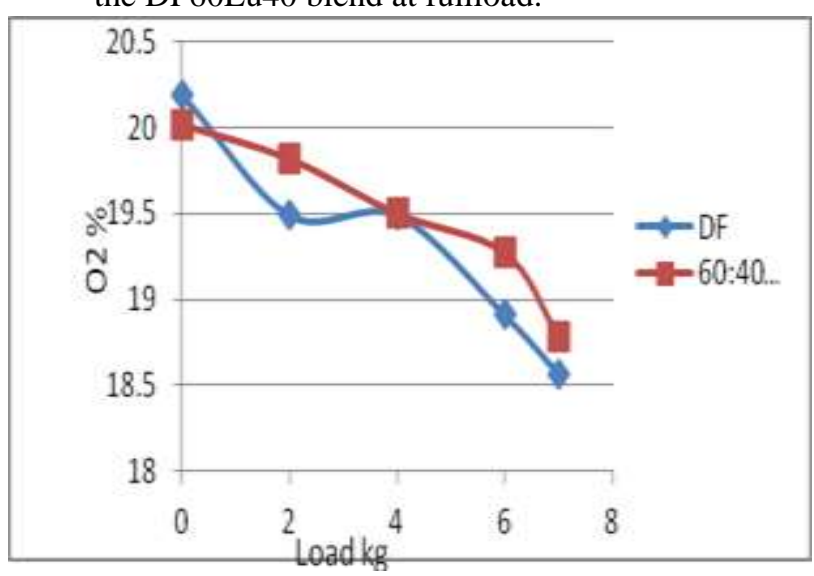

Variation of $\mathrm{O} 2$ emission with load for various DF60EUB40

\section{CONCLUSIONS}

In view of the check examination directed on a solitary chamber kirloskar AV1 motor making use of DF60EUB40 oil mixes. The accompanying huge ends are proven up.

1. The consequences confirmed that the mixing of DF60EUB40 is pretty an awful lot equivalent to sexually transmitted disease diesel brake heat efficiencyby

2 to 3 price much less from the same old diesel gasoline

2. The low warming estimation of the big variety of mixes became visible as comparative tothat

of popular diesel fuel

3. Increased unpredictability and diminished thickness are the benefit of those mixes.

4. Comparatively a slighter addition in $\mathrm{HC}$ outflow was located even as running with DF60EUB40 blend at alloads.

5. The final results indicates a $34 \%$ decrease in $\mathrm{CO}$ outflow and $37.5 \%$ decrease in $\mathrm{CO} 2$ emanations for DF60EUB40 mix.

6. The outcome suggests a comparable NOx for preferred diesel and DF60EUB40 blend.

\section{REFRENCES}

1. AyhanDemirbas, Progress and ongoing styles in biodiesel energizes, Energy Conversion and Management, 50 (2009),14-34.

2. 2. S.P. Singh, Dipti Singh,Biodiesel creation the usage of differentsources and portrayal of oils and their esters as the synthetic of diesel: An audit, Renewable and Sustainable Energy Reviews, 14 (2010), 200-216. 
3. Amar Pandhare, AtulPadalkar, Investigations on Performance and Emission Characteristics of Diesel Engine with Biodiesel (Jatropha Oil) and Its Blends, Hindawi Publishing Corporation - Journal of Renewable Energy, Research Article, 2013,1-eleven.

4. A.S Ramadhas, S. Jayaraj, C. Muraleedharan, Use of vegetable oils as I.C Engine energizes - a survey, Journal of Renewable Energy, 29(5), 2004, 727-742.

5. Five. M. Prabhahar, R. MuraliManohar, S. Sendilvelan, Performance and emanation Qualities of a diesel motor with distinct infusion pressuresusing biodiesel, Indian Journal of Science and Technology 5(6),2880-2884.

6. LyesTarabet, KhaledLoubar, Mohand Said Lounici, Samir Hanchi, MohandTazerout, Eucalyptus Biodiesel as an Alternative to Diesel Fuel: Preparation and Tests on DI Diesel Engine, Hindawi Publishing Corporation Journal of Biomedicine and Biotechnolog, Research Article,2012,1-eight.

7. Pradeep Kumar A.R, Annamalai. K, Premkartikkumar. SR, Experimental Investigation on Emission parameters of TransesterifiedAdelfa oil (Methyl ester of Nerium Oil), International Journal of ChemTech Research, 5(4),2013,1664-1670.

8. A.S Ramadhas, S. Jayaraj, C. Muraleedharan, Biodiesel creation from highFFA rubber seed oil, Fuels, 84 (2005),335-340. 